\title{
Comparison of Generalized Extreme Value, Log Normal and Weibull Distributions for Assessment of Low-Flow
}

\author{
N.Vivekanandan ${ }^{\star 凶}$ \\ Central Water and Power Research Station, P.O. Khadakwasla Research Station, Pune 411024, Maharashtra, India \\ ${ }^{\star}$ Corresponding author’s Email: anandaan@ rediffmail.com; (1) ORCiD: 0000-0002-7925-0349
}

\begin{abstract}
Assessment of low-flow is an important aspect for water quality management, reservoir storage design, determining minimum release policy and safe surface water withdrawals. For which, the annual minimum d-day average flow is generally adopted procedure for characterizing the low-flow in a stream, which can be obtained by averaging the flow using moving average method for ' $d$ ' consecutive days viz., 7-, 10-, 14- and 30- days. This paper presents a study on comparison of three probability distributions such as Generalized Extreme Value, 2-parameter Log Normal (LN2) and 2-parameter Weibull adopted in estimation of low-flow for river Cauvery at Kollegal gauging site. The parameters are determined by three methods viz., method of moments, maximum likelihood method and LMoments (LMO), and are used for estimation of low-flow. The adequacy of fitting probability distributions adopted in low-flow frequency analysis is evaluated by quantitative assessment using Goodness-of-Fit (viz., Chi-Square and Kolmogorov-Smirnov) and diagnostic (viz., correlation coefficient and root mean squared error) tests, and qualitative assessment using the fitted curves of the estimated low-flow. The results of quantitative and qualitative assessments indicate that LN2 (LMO) is better suited amongst three distributions for estimation of 7-, 10-, 14- and 30- day low-flows for river Cauvery at Kollegal site.
\end{abstract}

Keywords: Chi-Square, Correlation Coefficient, Low-flow, Generalized Extreme Value, Kolmogorov-Smirnov, LMoments, Log Normal, Root Mean Squared Error, Weibull

\section{INTRODUCTION}

Assessment of low-flow is an important aspect for water quality management, reservoir storage design, determining minimum release policy and safe surface water withdrawals (Tosunoglu et al., 2020). Numbers of indices viz., mean annual runoff, mean daily flow, median flow, Annual Minimum d-day Average Flow (AMdAF), absolute minimum flow are widely used to characterize the low-flow. Among these, AMdAF is generally adopted procedure for characterizing the low-flow in a stream, which can be obtained by averaging the flow using moving average method for ' $d$ ' consecutive days viz., 7-, 10-, 14- and 30- days. An associated, annual event based, low-flow statistic $\mathrm{q}(\mathrm{d}, \mathrm{T})$ gives a low-flow estimate, which is defined as the AMdAF that is expected to be occurred once in T-year return period (Kernell, 2012).

Out of number of available probability distributions, the Extreme Value Type-1 (EV1) (commonly known as Gumbel), Gamma (GAM), Generalized Extreme Value (GEV), 2-parameter Log Normal (LN2), Log Pearson Type-3 (LP3), Pearson Type-3 (P3) and 2-parameter Weibull (WB2) are most commonly used in Low-flow Frequency Analysis (LFA) (Kroll and Vogel, 2002; Peng et al., 2010; Blum et al., 2017). Ahn et al. (1998) applied the Power and SMEMAX (Small, MEdium and
MAXimum) transformation, LN2, LP3 and WB2 distributions to estimate the 7-day and 30-day low-flows for different return periods at four gauged points of the Ansung stream in Korea. Bowers et al. (2012) analyzed the seasonal river flow data and found both power law and LN2 distributions are relevant to dry seasons. They also found that the river flow data in wet seasons are typically better-fitted using LN2 than power law.

Farmer et al. (2015) recommended the use of inverse moments or negative moment orders for low flow series because the positive moment orders do not effectively capture the probabilistic lower tail behaviour of flows above a certain exceedance probability. Randall and Freehafer (2017) applied the regression method to study on low-flow statistics at ungauged sites in the Lower Hudson River Basin, New York. They found that the logarithmic transformation yielded less accurate equations inconsistent with some conceptualized relationships. Sapac et al. (2019) investigated the low- and high-flow characteristics of Karst catchments under climate change. Study by Hasan et al. (2021) revealed that LN2 distribution provided a good fit to annual minimum flow data at each station amongst four probability distributions (viz., GAM, EV1, LN2 and P3) for Selangor river carried out the LFA by adopting for Selangor river, Malaysia. In light of the above, for the present study, the GEV, LN2 
and WB2 distributions are adopted in Low-flow Frequency Analysis (LFA). Generally, Method of Moments (MoM) is applied for determination of parameters of the probability distributions (Durrans, 1996). But, the studies carried out by various researchers indicated that the estimated parameters of distributions fitted by the MoM are often less accurate than those obtained by other parameter estimation procedures viz., Maximum Likelihood Method (MLM) and L-Moments (LMO) (Jain et al., 2017; Bilkova, 2012). Therefore, in the present study, the MoM, MLM and LMO are applied for determination of the parameters of the distributions (viz., GEV, LN2 and WB2) and are used for estimation of lowflow. The adequacy of fitting probability distributions adopted in LFA is evaluated by quantitative assessment using non-parametric Goodness-of-Fit (viz., Chi-Square $\left(\chi^{2}\right)$ and Kolmogorov-Smirnov (KS)) and diagnostic (i.e., Correlation Coefficient (CC) and Root Mean Squared Error (RMSE)) tests, and qualitative assessment using the fitted curves of the estimated low-flow.

This paper presents the procedures applied in determining the MoM, MLM and LMO estimators of GEV, LN2 and WB2 distributions adopted in LFA for river Cauvery at Kollegal gauging site and the results obtained thereof.

\section{MATERIALS AND METHODS}

In the present study, the AMdAF series for different duration of 'd' viz., 7-, 10-, 14-, and 30-days is extracted from the daily stream flow data series and used in LFA. Table 1 presents the Cumulative Distribution Function $(\mathrm{CDF})$ with quantile estimator $(\mathrm{q}(\mathrm{T}))$ of three distributions (Vogel and Kroll, 1990; Heo et al., 2001) adopted in LFA. In Table $1, \mathrm{q}$ is the variable (i.e., AMdAF), $\xi$ is the location parameter, $\alpha$ is the scale parameter, $\beta$ is the shape parameter, $\mathrm{F}(\mathrm{q})$ is the $\mathrm{CDF}$ of $\mathrm{q}, \phi(\ldots)$ is the $\mathrm{CDF}$ of the standard normal distribution, $\mathrm{T}$ is the return period (in year) and $\mathrm{K}(\mathrm{T})$ is the frequency factor for a given return period (T) corresponding to Coefficient of Skewness (i.e., $\mathrm{CS}=0.0$ ). The parameters of the distributions are determined by MoM, MLM and LMO; and also used to estimate the value of $\mathrm{q}(\mathrm{T})$ for a return period $(\mathrm{T})$. The procedures involved in determining the parameters of the distributions are described in the text book titled 'Flood Frequency Analysis' (Rao and Hamed, 2000).

Table 1. CDF with quantile estimator of GEV, LN2 and WB2 distributions

\begin{tabular}{|c|c|c|}
\hline Distribution & Cumulative Distribution Function (CDF) & Quantile Estimator $(\mathbf{q}(\mathbf{T}))$ \\
\hline GEV & $F(q)=1-\exp \left(-\left[1-\frac{\beta(q-\xi)}{\alpha}\right]^{1 / \beta}\right), q>0, \alpha>0, \beta>0$ & $q(T)=\xi+\frac{\alpha}{\beta}\left(1-[\ln (1-(1 / T))]^{\beta}\right)$ \\
\hline LN2 & $F(q)=\phi\left(\frac{\ln (q)-\alpha}{\beta}\right), q>0, \beta>0$ & $\begin{array}{l}\mathrm{q}(\mathrm{T})=\exp (\alpha+\mathrm{K}(\mathrm{T}) \beta) \text { wherein } \\
\mathrm{K}(\mathrm{T})=4.91\left((1 / \mathrm{T})^{0.14}-(1-(1 / \mathrm{T}))^{0.14}\right)\end{array}$ \\
\hline WB2 & $F(q)=1-\exp \left(-\frac{q}{\alpha}\right)^{\beta}, q>0, \beta>0$ & $\mathrm{q}(\mathrm{T})=\alpha(-\ln (1-(1 / \mathrm{T})))^{1 / \beta}$ \\
\hline
\end{tabular}

\section{Goodness-of-Fit tests}

A non-parametric GoF tests viz., Chi-square $\left(\chi_{2}\right)$ and Kolmogorov-Smirnov (KS) are applied for checking the adequacy of fitting GEV, LN2 and WB2 distributions adopted in LFA. The theoretical descriptions of GoF tests statistic are presented in Table 2 . The rejection region of $\chi^{2}$ test statistic at the desired significance level $(\eta)$ is given by $\chi_{\mathrm{c}}^{2} \geq \chi_{1-\eta, \mathrm{NC}-\mathrm{m}-1}^{2}$. The theoretical values of GoF tests statistic for different significance level $(\eta)$ are available in the technical note on 'Goodness-of-Fit Tests for Statistical Distributions' (Charles Annis, 2009). If the computed values of GoF tests statistic given by the distribution are less than that of its theoretical value at the desired significance level then the selected distribution is considered to be adequate for LFA.

\section{Diagnostic test}

The selection of most suitable probability distribution with parameter estimation method for estimation of lowflow is made through diagnostic test using CC and RMSE. The theoretical expressions of CC and RMSE (Vivekanandan, 2020) are given as below:

$$
\begin{gathered}
\mathrm{CC}=\frac{\sum_{i=1}^{N}\left(q_{i}(0)-\overline{q(o)}\right)\left(q_{i}(e)-\overline{q(e)}\right)}{\sqrt{\sum_{i=1}^{N}\left(q_{i}(o)-\overline{q(o)}\right)^{2} \sum_{i=1}^{N}\left(q_{i}(e)-\overline{q(e)}\right)^{2}}} \\
\text { RMSE }=\left(\frac{1}{N} \sum_{i=1}^{N}\left(q_{i}(o)-q_{i}(e)\right)^{2}\right)^{1 / 2}
\end{gathered}
$$

where, $\mathrm{q}_{\mathrm{i}}(\mathrm{o})$ is the observed low-flow (q) of $\mathrm{i}^{\text {th }}$ sample and $\mathrm{q}_{\mathrm{i}}(\mathrm{e})$ is the estimated low-flow (q) of $\mathrm{i}^{\text {th }}$ sample, $\overline{\mathrm{q}(\mathrm{o})}$ is the average of the observed low-flows and $\overline{\mathrm{q}(\mathrm{e})}$ is the average of the estimated low-flows. The probability distribution with high $\mathrm{CC}$ (say, $\mathrm{CC}>0.9$ ) and minimum RMSE is identified as a better-suited for estimation of low-flow.

\section{Application}

In this paper, a study on comparison of GEV, LN2 and WB2 probability distributions for estimation of lowflow for river Cauvery at Kollegal gauging site is carried out. The Cauvery river rises at an elevation of $1341 \mathrm{~m}$ at Talakaveri on the Brahmagiri range near Cherangala village of Kodagu district of Karnataka (Ghosh et al., 2018). The river basin lies between $75^{\circ} 27^{\prime}$ to $79^{\circ} 54^{\prime}$ east longitudes and $10^{\circ} 9^{\prime}$ to $13^{\circ} 30^{\prime}$ north latitudes. The total 
length of the river from origin to outfall is $800 \mathrm{~km}$ and drains into the Bay of Bengal. The river basin extends over states of Tamil Nadu, Karnataka, Kerala and Union Territory of Puducherry draining an area of $81155 \mathrm{~km}^{2}$, which is nearly $2.7 \%$ of the total geographical area of the country. The Kollegal gauging site is located between $77^{\circ}$ $06^{\prime} 00^{\prime \prime}$ east longitude and $12^{\circ} 11^{\prime} 21^{\prime \prime}$ north latitude in Chamarajanagar district of Karnataka state, which is one of the tributary of Cauvery river. The catchment area of the Kollegal site is $21082 \mathrm{~km}^{2}$. Figure 1 shows the location map of the study area. The daily stream flow data observed at Kollegal gauging site for the period 1990 to 2018 is used for LFA.

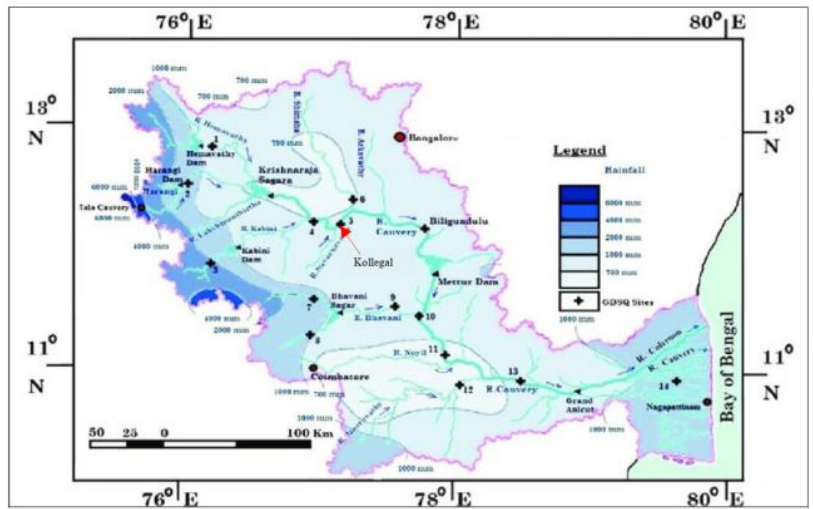

Figure1. Location map of the study area

\section{RESULTS AND DISCUSSION}

In the present study, the AMdAF series for different duration of 'd' viz., 7-, 10-, 14-, and 30- days was extracted from the daily stream flow data series, and are used for LFA. The descriptive statistics of the AMdAF series for different duration of 'd' viz., 7-, 10-, 14- and 30- days are presented in Table 3.

\section{Estimation of Low-flow using probability distributions}

By applying the procedures as described above, the parameters of GEV, LN2 and WB2 distributions were determined by MoM, MLM and LMO for the AMdAF series for different duration of 'd' viz., 7-, 10-, 14- and 30days. These parameters were used to estimate the low-flow for different return period and the results are presented in Tables 4 to 7 .

From Table 4, it is found that the estimated 7-day low-flow using WB2 (LMO) is lesser than those values of other distributions for a return period from 10-year to 100year. Also, from Tables 5 to 7 , it is noted that the low-flow estimates for different duration of 'd' viz., 10-, 14- and 30days obtained from WB2 (MLM) distribution are lower than those values of other probability distributions adopted in LFA for the return periods from 10-year to 100-year.

Table 2.Theoretical descriptions of GoF tests statistic

\begin{tabular}{|c|c|c|c|}
\hline GoF test & Test statistic & Descri & ion of symbols \\
\hline \multirow{4}{*}{$\chi^{2}$} & \multirow{4}{*}{$\chi_{c}^{2}=\sum_{j=1}^{N C} \frac{\left(O_{j}(q)-E_{j}(q)\right)^{2}}{E_{j}(q)}$} & $\chi_{\mathrm{c}}^{2}$ & : Computed value of $\chi^{2}$ statistic by the probability distribution. \\
\hline & & $\mathrm{O}_{\mathrm{j}}(\mathrm{q})$ & : Observed frequency value (q) of $\mathrm{j}^{\text {th }}$ class. \\
\hline & & $\mathrm{E}_{\mathrm{j}}(\mathrm{q})$ & : Expected frequency value (q) of $\mathrm{j}^{\text {th }}$ class. \\
\hline & & $\mathrm{NC}$ & : Number of frequency classes. \\
\hline \multirow{3}{*}{ KS } & \multirow{3}{*}{$\mathrm{KS}=\operatorname{Max} \sum_{\mathrm{i}=1}^{\mathrm{N}}\left|\mathrm{F}_{\mathrm{e}}\left(\mathrm{q}_{\mathrm{i}}\right)-\mathrm{F}_{\mathrm{D}}\left(\mathrm{q}_{\mathrm{i}}\right)\right|$} & & $\begin{array}{l}\text { Empirical CDF of } \mathrm{q}_{\mathrm{i}} \text { using Weibull plotting position formula }(\mathrm{P}=\mathrm{r} /(\mathrm{N}+1)) \\
\text { wherein ' } \mathrm{r} \text { ' is the rank assigned to the samples arranged in ascending order } \\
\left.\text { (i.e., } \mathrm{q}_{1}<\mathrm{q}_{2}<\mathrm{q}_{3}<\ldots \ldots \mathrm{q}_{\mathrm{N}}\right) \text {. }\end{array}$ \\
\hline & & $\mathrm{F}_{\mathrm{D}}\left(\mathrm{q}_{\mathrm{i}}\right)$ & : Derived CDF of $\mathrm{q}_{\mathrm{i}}$ using probability distribution. \\
\hline & & $\mathrm{N}$ & : Sample size. \\
\hline
\end{tabular}

Table 3. Descriptive statistics of the AMdAF series

\begin{tabular}{lcccc}
\hline AMdAF series & Average $\left(\mathbf{m}^{\mathbf{3}} / \mathbf{s}\right)$ & Standard deviation $\mathbf{( \mathbf { m } ^ { 3 } / \mathbf { s } )}$ & Coefficient of skewness & Coefficient of kurtosis \\
\hline \multirow{2}{*}{$\mathrm{d}=7$} & 23.632 & 7.853 & 0.220 & -1.215 \\
& $(3.106)$ & $(0.348)$ & $(-0.242)$ & $(-0.925)$ \\
$\mathrm{N}=10$ & 26.014 & 9.274 & 0.768 & 0.907 \\
& $(3.197)$ & $(0.360)$ & $(-0.158)$ & $(-0.261)$ \\
$\mathrm{d}=14$ & 27.996 & 10.305 & 0.960 & 1.858 \\
& $(3.268)$ & $(0.368)$ & $(-0.165)$ & $(-0.012)$ \\
$\mathrm{d}=30$ & 33.864 & 11.929 & 0.809 & 1.581 \\
& $(3.462)$ & $(0.359)$ & $(-0.266)$ & $(-0.081)$ \\
\hline
\end{tabular}

Numbers given within a brackets indicates the descriptive statistics of the log-transformed data of AMdAF series. 
Table 4. Estimated 7-day low-flow for different return periods using GEV, LN2 and WB2 distributions

\begin{tabular}{|c|c|c|c|c|c|c|c|c|c|}
\hline \multirow{3}{*}{$\begin{array}{l}\text { Return } \\
\text { period } \\
\text { (year) }\end{array}$} & \multicolumn{9}{|c|}{ 7-day low-flow $\left(\mathrm{m}^{3} / \mathrm{s}\right)$} \\
\hline & \multicolumn{3}{|c|}{ GEV } & \multicolumn{3}{|c|}{ LN2 } & \multicolumn{3}{|c|}{ WB2 } \\
\hline & MoM & MLM & LMO & MoM & MLM & LMO & MoM & MLM & LMO \\
\hline 1.01 & 42.61 & 44.72 & 44.21 & 47.67 & 49.52 & 51.23 & 41.72 & 41.33 & 42.23 \\
\hline 2 & 23.36 & 23.00 & 23.05 & 22.43 & 22.34 & 22.33 & 23.59 & 23.69 & 23.55 \\
\hline 5 & 16.68 & 16.68 & 16.45 & 17.08 & 16.76 & 16.55 & 16.77 & 16.99 & 16.61 \\
\hline 10 & 13.51 & 13.73 & 13.53 & 14.81 & 14.42 & 14.15 & 13.38 & 13.63 & 13.18 \\
\hline 20 & 11.17 & 11.45 & 11.47 & 13.17 & 12.73 & 12.43 & 10.78 & 11.03 & 10.56 \\
\hline 25 & 10.54 & 10.81 & 10.93 & 12.73 & 12.28 & 11.97 & 10.06 & 10.32 & 9.84 \\
\hline 50 & 8.89 & 9.04 & 9.57 & 11.54 & 11.07 & 10.75 & 8.14 & 8.39 & 7.93 \\
\hline 75 & 8.11 & 8.12 & 8.95 & 10.95 & 10.48 & 10.14 & 7.20 & 7.44 & 6.99 \\
\hline 100 & 7.61 & 7.52 & 8.57 & 10.56 & 10.09 & 9.76 & 6.60 & 6.84 & 6.39 \\
\hline
\end{tabular}

GEV: Generalized Extreme Value; LN2: 2-parameter Log Normal; WB2: 2-parameter Weibull; MoM: Method of Moments; MLM: Maximum Likeihood Method; LMO: L-Moments

Table 5. Estimated 10-day low-flow for different return periods using GEV, LN2 and WB2 distributions

\begin{tabular}{|c|c|c|c|c|c|c|c|c|c|}
\hline \multirow{3}{*}{$\begin{array}{l}\text { Return } \\
\text { period } \\
\text { (year) }\end{array}$} & \multicolumn{9}{|c|}{ 10-day low-flow $\left(\mathrm{m}^{3} / \mathrm{s}\right)$} \\
\hline & \multicolumn{3}{|c|}{ GEV } & \multicolumn{3}{|c|}{ LN2 } & \multicolumn{3}{|c|}{ WB2 } \\
\hline & MoM & MLM & LMO & MoM & MLM & LMO & MoM & MLM & LMO \\
\hline 1.01 & 52.23 & 53.27 & 51.82 & 54.86 & 55.78 & 57.49 & 47.87 & 48.35 & 47.63 \\
\hline 2 & 24.70 & 24.83 & 24.83 & 24.50 & 24.47 & 24.47 & 25.83 & 25.79 & 25.85 \\
\hline 5 & 17.76 & 18.06 & 17.69 & 18.31 & 18.17 & 17.98 & 17.86 & 17.71 & 17.93 \\
\hline 10 & 15.05 & 15.05 & 14.83 & 15.73 & 15.55 & 15.30 & 13.99 & 13.81 & 14.08 \\
\hline 20 & 13.32 & 12.79 & 12.95 & 13.87 & 13.68 & 13.40 & 11.07 & 10.88 & 11.16 \\
\hline 25 & 12.90 & 12.16 & 12.49 & 13.37 & 13.18 & 12.89 & 10.27 & 10.09 & 10.37 \\
\hline 50 & 11.89 & 10.45 & 11.37 & 12.04 & 11.84 & 11.53 & 8.17 & 7.99 & 8.27 \\
\hline 75 & 11.47 & 9.57 & 10.88 & 11.38 & 11.18 & 10.86 & 7.15 & 6.98 & 7.24 \\
\hline 100 & 11.21 & 9.00 & 10.60 & 10.96 & 10.75 & 10.44 & 6.51 & 6.34 & 6.60 \\
\hline
\end{tabular}

GEV: Generalized Extreme Value; LN2: 2-parameter Log Normal; WB2: 2-parameter Weibull; MoM: Method of Moments; MLM: Maximum Likeihood Method; LMO: L-Moments

Table 6. Estimated 14-day low-flow for different return periods using GEV, LN2 and WB2 distributions

\begin{tabular}{|c|c|c|c|c|c|c|c|c|c|}
\hline \multirow{3}{*}{$\begin{array}{l}\text { Return } \\
\text { period } \\
\text { (year) }\end{array}$} & \multicolumn{9}{|c|}{ 14-day low-flow $\left(\mathrm{m}^{3} / \mathrm{s}\right)$} \\
\hline & \multicolumn{3}{|c|}{ GEV } & \multicolumn{3}{|c|}{ LN2 } & \multicolumn{3}{|c|}{ WB2 } \\
\hline & MoM & MLM & LMO & MoM & MLM & LMO & MoM & MLM & LMO \\
\hline 1.01 & 58.60 & 58.28 & 56.57 & 60.29 & 61.03 & 62.67 & 52.58 & 53.28 & 51.82 \\
\hline 2 & 26.18 & 26.64 & 26.63 & 26.27 & 26.26 & 26.26 & 27.72 & 27.64 & 27.77 \\
\hline 5 & 18.92 & 19.28 & 18.87 & 19.46 & 19.36 & 19.18 & 18.90 & 18.67 & 19.13 \\
\hline 10 & 16.29 & 16.03 & 15.79 & 16.64 & 16.51 & 16.28 & 14.67 & 14.40 & 14.95 \\
\hline 20 & 14.69 & 13.60 & 13.80 & 14.62 & 14.48 & 14.21 & 11.50 & 11.22 & 11.79 \\
\hline 25 & 14.32 & 12.93 & 13.31 & 14.08 & 13.93 & 13.66 & 10.65 & 10.37 & 10.94 \\
\hline 50 & 13.45 & 11.09 & 12.13 & 12.63 & 12.48 & 12.20 & 8.40 & 8.13 & 8.68 \\
\hline 75 & 13.10 & 10.15 & 11.62 & 11.92 & 11.77 & 11.48 & 7.31 & 7.05 & 7.59 \\
\hline 100 & 12.89 & 9.53 & 11.33 & 11.46 & 11.31 & 11.02 & 6.63 & 6.38 & 6.90 \\
\hline
\end{tabular}

GEV: Generalized Extreme Value; LN2: 2-parameter Log Normal; WB2: 2-parameter Weibull; MoM: Method of Moments; MLM: Maximum Likeihood Method; LMO: L-Moments

Table 7. Estimated 30-day low-flow for different return periods using GEV, LN2 and WB2 distributions

\begin{tabular}{|c|c|c|c|c|c|c|c|c|c|}
\hline \multirow{3}{*}{$\begin{array}{l}\text { Return } \\
\text { period } \\
\text { (year) }\end{array}$} & \multicolumn{9}{|c|}{ 30-day low-flow $\left(\mathrm{m}^{3} / \mathrm{s}\right)$} \\
\hline & \multicolumn{3}{|c|}{ GEV } & \multicolumn{3}{|c|}{ LN2 } & \multicolumn{3}{|c|}{ WB2 } \\
\hline & MoM & MLM & LMO & MoM & MLM & LMO & MoM & MLM & LMO \\
\hline 1.01 & 67.95 & 65.86 & 64.80 & 70.86 & 72.58 & 74.41 & 61.85 & 62.72 & 61.27 \\
\hline 2 & 32.08 & 32.76 & 32.81 & 31.94 & 31.88 & 31.88 & 33.66 & 33.55 & 33.70 \\
\hline 5 & 23.27 & 23.69 & 23.32 & 23.95 & 23.68 & 23.48 & 23.39 & 23.08 & 23.57 \\
\hline 10 & 19.88 & 19.52 & 19.23 & 20.61 & 20.28 & 20.01 & 18.38 & 18.02 & 18.60 \\
\hline 20 & 17.74 & 16.33 & 16.41 & 18.20 & 17.84 & 17.53 & 14.59 & 14.21 & 14.82 \\
\hline 25 & 17.23 & 15.44 & 15.69 & 17.55 & 17.18 & 16.87 & 13.56 & 13.18 & 13.79 \\
\hline 50 & 16.00 & 12.97 & 13.88 & 15.82 & 15.44 & 15.11 & 10.82 & 10.45 & 11.05 \\
\hline 75 & 15.48 & 11.70 & 13.07 & 14.97 & 14.58 & 14.24 & 9.49 & 9.13 & 9.71 \\
\hline 100 & 15.18 & 10.86 & 12.58 & 14.42 & 14.02 & 13.69 & 8.65 & 8.30 & 8.87 \\
\hline
\end{tabular}

GEV: Generalized Extreme Value; LN2: 2-parameter Log Normal; WB2: 2-parameter Weibull; MoM: Method of Moments; MLM: Maximum Likeihood Method; LMO: L-Moments 


\section{Low-Flow frequency curves}

The estimated low-flows were used to develop the Low-Flow Frequency Curves (LFCs) and are presented in Figure 2 (a to d). From LFCs, it can be seen that (i) there is a line of agreement between the observed and estimated low-flows using LN2 when compared with GEV and WB2; and (ii) the estimated low-flows using LN2 (LMO) are nearer to the observed low-flows.

\section{Analysis of results based on GoF tests}

GoF tests statistic values for the AMdAF series for different duration of 'd' viz., 7-, 10-, 14-, and 30-days were computed and are presented in Tables 8 and 9. In the present study, the number of frequency classes (NC) is considered as five and accordingly the degree of freedom (NC-m-1) is considered as one for GEV while two for LN2 and WB2 while computing the $\chi^{2}$ statistic values. The theoretical values of $\chi^{2}$ statistic at $5 \%$ level of significance with reference to the degree of freedom are observed as 3.841 for GEV whereas 5.991 for LN2 and WB2. Likewise, the theoretical value of KS statistic at 5\% level of significance with reference to the number of samples considered in LFA is 0.246 . From GoF tests results, it is noted that:

$>\chi^{2}$ test results didn't confirm the applicability of GEV, LN2 and WB2 (using MoM, MLM and LMO) distributions for modelling the AM7AF data.

$>\chi^{2}$ test results supported the use of GEV, LN2 and WB2 (using MoM, MLM and LMO) for modelling the $\mathrm{AM} 10 \mathrm{AF}, \mathrm{AM} 14 \mathrm{AF}$ and AM30AF series.

$>\mathrm{KS}$ test results confirmed the applicability of GEV, LN2 and WB2 distributions (using MoM, MLM and LMO) for modelling the AMdAF series for different duration of 'd' viz., 7-, 10-, 14- and 30-days.

Table 8. Computed values of $\chi^{2}$ test statistic by GEV, LN2 and WB2 distributions

\begin{tabular}{|c|c|c|c|c|c|c|c|c|c|}
\hline \multirow{3}{*}{$\begin{array}{l}\text { AMdAF } \\
\text { series }\end{array}$} & \multicolumn{9}{|c|}{ Computed values of $\chi^{2}$ test statistic } \\
\hline & \multicolumn{3}{|c|}{ GEV } & \multicolumn{3}{|c|}{ LN2 } & \multicolumn{3}{|c|}{ WB2 } \\
\hline & MoM & MLM & LMO & MoM & MLM & LMO & MoM & MLM & LMO \\
\hline $\mathrm{d}=7$ & 9.103 & 6.344 & 6.344 & 6.621 & 6.621 & 6.624 & 9.103 & 9.125 & 8.069 \\
\hline$d=10$ & 1.862 & 1.172 & 1.172 & 4.621 & 4.621 & 4.624 & 1.517 & 1.520 & 1.517 \\
\hline$d=14$ & 1.862 & 1.863 & 1.862 & 0.828 & 0.828 & 0.840 & 2.552 & 1.862 & 1.172 \\
\hline$d=30$ & 3.821 & 3.821 & 3.821 & 0.483 & 0.483 & 0.485 & 2.552 & 2.552 & 2.552 \\
\hline
\end{tabular}

GEV: Generalized Extreme Value; LN2: 2-parameter Log Normal; WB2: 2-parameter Weibull; MoM: Method of Moments; MLM: Maximum Likeihood Method; LMO: L-Moments

Table 9. Computed values of KS test statistic by GEV, LN2 and WB2 distributions

\begin{tabular}{|c|c|c|c|c|c|c|c|c|c|}
\hline \multirow{3}{*}{$\begin{array}{l}\text { AMdAF } \\
\text { series }\end{array}$} & \multicolumn{9}{|c|}{ Computed values of KS test statistic } \\
\hline & \multicolumn{3}{|c|}{ GEV } & \multicolumn{3}{|c|}{ LN2 } & \multicolumn{3}{|c|}{ WB2 } \\
\hline & MoM & MLM & LMO & MoM & MLM & LMO & MoM & MLM & LMO \\
\hline $\mathrm{d}=7$ & 0.111 & 0.095 & 0.095 & 0.124 & 0.125 & 0.128 & 0.121 & 0.122 & 0.118 \\
\hline$d=10$ & 0.092 & 0.089 & 0.089 & 0.110 & 0.112 & 0.115 & 0.082 & 0.085 & 0.082 \\
\hline $\mathrm{d}=14$ & 0.071 & 0.067 & 0.063 & 0.085 & 0.085 & 0.090 & 0.080 & 0.081 & 0.083 \\
\hline$d=30$ & 0.072 & 0.076 & 0.079 & 0.073 & 0.073 & 0.075 & 0.089 & 0.087 & 0.086 \\
\hline
\end{tabular}

GEV: Generalized Extreme Value; LN2: 2-parameter Log Normal; WB2: 2-parameter Weibull; MoM: Method of Moments; MLM: Maximum Likeihood Method; LMO: L-Moments

Analysis of results based on diagnostic test

In addition to GoF tests, the performance of GEV, LN2 and WB2 distributions adopted in LFA using the AMdAF series for different duration of 'd' viz., 7-, 10-,
14-, and 30-days was evaluated by CC and RMSE. The $\mathrm{CC}$ and RMSE values for the AMdAF series for different durations of ' $\mathrm{d}$ ' were computed by GEV, LN2 and WB2 distributions and are presented in Tables 10 and 11.

Table 10. CC values given by GEV, LN2 and WB2 distributions

\begin{tabular}{|c|c|c|c|c|c|c|c|c|c|}
\hline \multirow{3}{*}{$\begin{array}{l}\text { AMdAF } \\
\text { series }\end{array}$} & \multicolumn{9}{|c|}{ Correlation Coeffiicient (CC) } \\
\hline & \multicolumn{3}{|c|}{ GEV } & \multicolumn{3}{|c|}{ LN2 } & \multicolumn{3}{|c|}{ WB2 } \\
\hline & MoM & MLM & LMO & MoM & MLM & LMO & MoM & MLM & LMO \\
\hline $\mathrm{d}=7$ & 0.980 & 0.967 & 0.981 & 0.971 & 0.970 & 0.969 & 0.979 & 0.978 & 0.979 \\
\hline $\mathrm{d}=10$ & 0.983 & 0.983 & 0.983 & 0.985 & 0.985 & 0.985 & 0.973 & 0.974 & 0.973 \\
\hline $\mathrm{d}=14$ & 0.979 & 0.978 & 0.978 & 0.982 & 0.982 & 0.982 & 0.967 & 0.968 & 0.966 \\
\hline $\mathrm{d}=30$ & 0.979 & 0.978 & 0.977 & 0.982 & 0.982 & 0.982 & 0.971 & 0.972 & 0.971 \\
\hline
\end{tabular}

GEV: Generalized Extreme Value; LN2: 2-parameter Log Normal; WB2: 2-parameter Weibull; MoM: Method of Moments; MLM: Maximum Likeihood Method; LMO: L-Moments 
From Table 10, it is observed that there is generally good correlation between the observed and estimated lowflows using GEV, LN2 and WB2; and the CC values vary between 0.966 and 0.985 . From Table 11, it is noticed that the RMSE given by GEV (LMO) is minimum for AM7AF while LN2 (LMO) for AM10AF, AM14AF and AM30AF series when compared with those values of other probability distributions adopted in LFA while MoM, MLM and LMO are applied for determining the parameters of the distributions. But, for AM7AF series, it is noted that the fitted line of the estimated low-flows using LN2 (LMO) is closer to the observed data though the RMSE of LN2 (LMO) is higher than those values of GEV and WB2. On the basis of quantitative and qualitative assessments, it is identified that the LN2 (LMO) is better suited amongst three distributions studied in LFA for estimation of 7-, 10-, 14- and 30-days lowflows for Cauvery river at Kollegal site.

Table 11. RMSE values given by GEV, LN2 and WB2 distributions

\begin{tabular}{|c|c|c|c|c|c|c|c|c|c|}
\hline \multirow{3}{*}{ AMdAF series } & \multicolumn{9}{|c|}{ Roote Mean Sqaure Error (RMSE) $\left(\mathrm{m}^{3} / \mathrm{s}\right)$} \\
\hline & \multicolumn{3}{|c|}{ GEV } & \multicolumn{3}{|c|}{ LN2 } & \multicolumn{3}{|c|}{ WB2 } \\
\hline & MoM & MLM & LMO & MoM & MLM & LMO & MoM & MLM & LMO \\
\hline $\mathrm{d}=7$ & 1.577 & 1.805 & 1.527 & 1.964 & 1.909 & 1.922 & 1.638 & 1.687 & 1.597 \\
\hline $\mathrm{d}=10$ & 1.777 & 1.774 & 1.771 & 1.851 & 1.763 & 1.652 & 2.132 & 2.092 & 2.156 \\
\hline$d=14$ & 2.205 & 2.225 & 2.245 & 2.196 & 2.123 & 1.955 & 2.616 & 2.541 & 2.689 \\
\hline $\mathrm{d}=30$ & 2.530 & 2.560 & 2.589 & 2.530 & 2.391 & 2.301 & 2.837 & 2.776 & 2.890 \\
\hline
\end{tabular}

GEV: Generalized Extreme Value; LN2: 2-parameter Log Normal; WB2: 2-parameter Weibull; MoM: Method of Moments; MLM: Maximum Likeihood Method; LMO: L-Moments
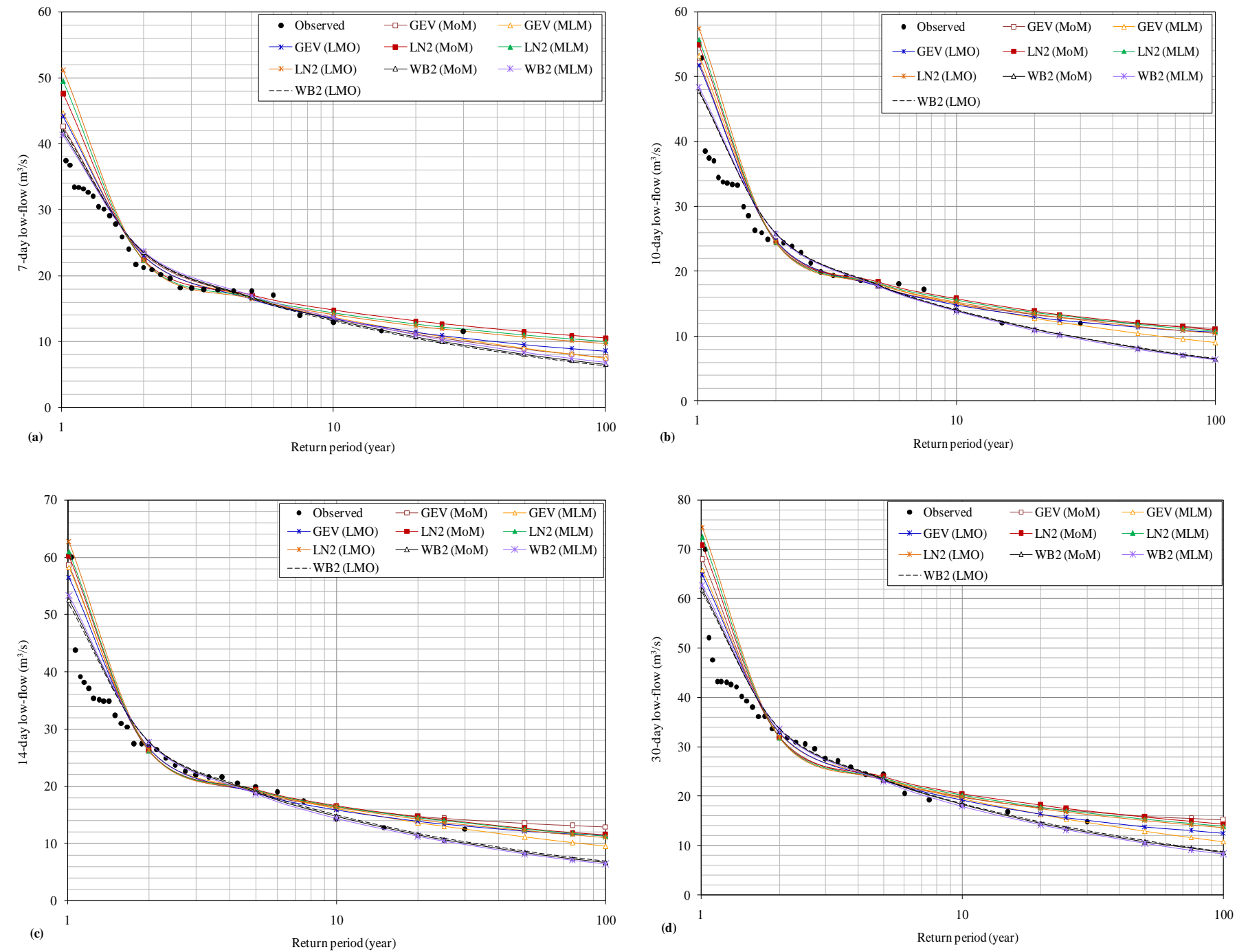

Figure 2. Low-flow frequency curves for river Cauvery at Kollegal site 


\section{CONCLUSIONS}

This paper presented a study on comparison of three probability distributions (viz., GEV, LN2 and WB2) adopted in frequency analysis of low-flow for river Cauvery at Kollegal gauging site that are evaluated by quantitative assessment using GoF (viz., Chi-square and Kolmogrov-Smirnov) and diagnostic (viz., Correlation Coefficient and Root Mean Squared Error) tests and qualitative assessment using the fitted curves of the estimated low-flows. The parameters of the distributions were determined by MoM, MLM and LMO, and are used for estimation of low-flow using the low-flow statistic viz., $\mathrm{q}(\mathrm{d}, \mathrm{T})$ for different duration of 'd' viz., 7-, 10-, 14and 30-days and for different return periods $(\mathrm{T})$ vary from 1.01-year to 100-year. Based on the results of data analysis, the conclusions drawn from the study were summarized and presented below.

$>\chi^{2}$ test results supported the use of GEV, LN2 and WB2 (using MoM, MLM and LMO) for modelling the AM10AF, AM14AF and AM30AF series.

$>\mathrm{KS}$ test results confirmed the applicability of GEV, LN2 and WB2 distributions (using MoM, MLM and LMO) for LFA using the AMdAF series for different duration of 'd' viz., 7-, 10-, 14- and 30-days.

$>$ Low-flow estimates for different duration of ' $\mathrm{d}$ ' viz., 10-, 14- and 30-days obtained from WB2 (MLM) distribution are lower than those values of GEV (using MoM, MLM and LMO), LN2 (using MoM, MLM and LMO) and WB2 (using MoM and LMO) for the return periods from 10 -year to 100 -year.

$>\mathrm{CC}$ values given by GEV, LN2 and WB2 distributions indicated that there is a good correlation between the observed and estimated low-flows and these values vary between 0.966 and 0.985 .

$>$ RMSE of LN2 (LMO) was found as minimum for AM10AF, AM14AF and AM30AF series whereas GEV (LMO) for AM7AF when compared with those values of other distributions adopted in LFA.

$>$ Qualitative assessment (plots of the LFA results) of the outcomes was weighed with RMSE and accordingly LN2 (LMO) is found as better suited distribution for estimation of 7-, 10-, 14- and 30- day low-flows.

The study suggested that the estimated 7-, 10-, 14- and 30-days low-flows using LN2 (LMO) distribution could be adopted for various applications such as water quality management, reservoir storage design, determining minimum release policy and safe surface water withdrawals.

\section{DECLARATIONS}

\section{Acknowledgement}

The author is thankful to the Director, Central Water and Power Research Station, Pune, for providing the research facilities to carry out the study.

\section{Conflict of interest}

I hereby state that there is no conflict of interest whatsoever with any third party.

\section{REFERENCES}

Ahn TJ, Lyu HJ, Yo WS and Park JE. (1998). Frequency analysis of low flows at gaged points of the Ansung stream. KSCE Journal of Civil Engineering, 2(1): 2333. https://doi.org/10.1007/BF02830468.

Bilkova D. (2012). Lognormal distribution and using Lmoment method for estimating its parameters. Journal of Mathematical Models and Methods in Applied Sciences, 1(6): 30-44. Google Scholar.

Blum AG, Archfield SA and Vogel RM. (2017). On the probability distribution of daily streamflow in the United States. Hydrology and Earth System Sciences, 21(6): 3093-3103. https://doi.org/10.5194/hess-213093-2017.

Bowers MC, Tung WW and Gao JB. (2012). On the distributions of seasonal river flows: Lognormal or power law?. Water Resources Research, 48: 1-12. https://doi.org/10.1029/2011WR011308.

Charles Annis PE. (2009). Goodness-of-Fit tests for statistical distributions. Google Scholar.

Durrans SR. (1996). Low-flow analysis with a conditional Weibull tail model. Water Resources Research, 32(6): 1749-1760. https://doi.org/10.1029/96WR00788.

Farmer WH, Over TM and Vogel RM. (2015). Multiple regression and inverse moments improve the characterization of the spatial scaling behaviour of daily streamflows in the Southeast United States. Water Resources Research, 51(3): 1775-1796. https://doi.org/10.1002/2014WR015924.

Ghosh N, Bandyopadhyay J and Thakur J. (2018). Conflict over Cauvery Waters: Imperatives for Innovative Policy Options. Observer Research Foundation, New Delhi. Google Scholar.

Hasan HH, Razali SFM, Muhammad NS and Hamzah FM. (2021).Assessment of probability distributions and analysis of the minimum storage draft rate in the equatorial region. Natural Hazards Earth System Science, 21(1): 1-19. https://doi.org/10.5194/nhess21-1-2021.

Heo JH, Salas JD and Kim KD. (2001). Estimation of confidence intervals of the quantiles for the Weibull distribution. Stochastic Environmental Research and Risk Assessment, 15(4): 284-309. https://doi.org/ 10.1007/s004770100071.

Jain SK, Agarwal PK and Singh VP. (2007). Hydrology and Water Resources in India. Water Science \& Technology Library, Springer Link Publications, Netherlands. Google Scholar.

Kernell GR. (2012). Estimation of low-flow duration discharges in Massachusetts. United States Geological Survey, Paper No. 2418. Google Scholar. 
KrollCN and Vogel RM. (2002). Probability distribution of low stream flow series in the United States. Journal of Hydrologic Engineering, 7(2): 137-146. https:// doi.org/10.1061/(ASCE)1084-0699(2002)7:2(137).

Peng S, Xi C, Si-min Q, Zhi-cai Z and Jian-liang M. (2010). Regional frequency analysis of low flow based on L moments: Case study in Karst Area, Southwest China. Journal of Hydrologic Engineering, 15(5): 370-377. https://doi.org/10.1061/(ASCE)HE. 1943-5584.0000206.

Randall AD and Freehafer DA. (2017). Estimation of lowflow statistics at ungauged sites on streams in the Lower Hudson River Basin. US Geological Survey Investigations Report-5019, 1-42. Google Scholar.

Rao AR and Hamed KH. (2000). Flood frequency analysis. CRC Publications, New York. Google Scholar.
Sapac K, Medved A, Rusjan S and Bezak N. (2019). Investigation of low- and high-flow characteristics of Karst catchments under climate change. Water, 11(5): 1-19. https://doi.org/10.3390/w11050925.

Tosunoglu F, Salvadori G and Yilmaz M. (2020). Multivariate assessment of low-flow hazards via copulas: The case study of the Çoruh basin (Turkey). Water, 12(10): 1-19. https://doi.org/10.3390/w12102848.

Vivekanandan N. (2020). A Comparative study on Gumbel and LP3 probability distributions for estimation of extreme rainfall. International Journal of Water Resources Engineering, 6(1): 21-33. Google Scholar.

Vogel RM and Kroll CN. (1990). Generalized low-flow frequency relationships for ungauged sites in Massachusetts. Water Resources Bulletin, 26(2): 241-253. https://DOI:10.1111/J.1752-1688.1990.TB01367.X. 